\title{
YOUR MEMBER CONNECTION
}

Meet the TMS members who have contributed to or are featured in this issue of JOM. To join the TMS network, visit www.tms.org/Society/Membership.aspx.

\section{JOM AUTHORS AND ADVISORS}

Bai, Chenguang is a professor at the School of Materials Science and Engineering, Chongqing University, China. Dr. Bai is a one-year member of TMS.

Barati, Mansoor is an assistant professor with the Department of Materials Science and Engineering at the University of Toronto, Canada. Dr. Barati is a one-year member of TMS.

Ciftja, Arjan is a research scientist at SINTEF Materials and Chemistry, Department of Metallurgy in Trondheim, Norway. He earned his Ph.D. (2009) in Materials Science at the Norwegian University of Science and Technology. Dr. Ciftja is a five-year member of TMS and the JOM advisor from the Recycling and Environmental Technologies Committee.

Guillen, Donna Post is a Group Lead in the Advanced Process and Decision Systems Department at the Idaho National Laboratory, operated for the U.S. Department of Energy. She earned a B.S. in Mechanical Engineering from Rutgers University, an M.S. in Aeronautics from the California Institute of Technology, and a Ph.D. (2005) in Engineering and Applied Science from Idaho State University. She has authored/co-authored over 80 technical publications in the form of books, reports, journal articles, and conference papers. Dr. Guillen was recently elected Vice-Chair of the TMS Energy Committee, and is a two-year member of TMS.

Jung, In-Ho is an assistant professor in the Department of Mining and Materials Engineering at McGill University, His major research interest is the thermodynamic modeling of inorganic materials related to pyrometallurgical process and alloy design and its application to process simulation, $\mathrm{He}$ has published more than 100 journal and conference papers. He is a co-developer of the FactSage thermochemical software Dr. Jung earned his Ph.D. (2003) in Metallurgical Engineering at Ecole Polytechnique and is a three-year member of TMS.
Krystad, Egil is a Ph.D. candidate in the Department of Materials Science and Engineering at the Norwegian University of Science and Technology, where he also earned his M.S. (2008) in Photovoltaics. Mr. Krystad is a two-year student member of TMS.

Lv, Xuewei is a professor in the College of Materials Science and Engineering at Chongqing University, China where he also earned his Ph.D. (2012) in Metallurgical Engineering. Dr. Lv is a two-year member of TMS.

Meteleva-Fischer, Yulia is a postdoctoral scientist with a background in physical chemistry and an interest in projects related to sustainable energy and materials. Her areas of expertise are inorganic and physical chemistry of semiconducting films and nanocomposites, solid-state physics of reactions of charge carriers and semiconducting materials, and materials science of silicon refining. Dr. Meteleva-Fischer's list of publications includes 41 articles, eight conference papers, 53 conference contributions, one book chapter, and a Ph.D. thesis. She earned her Ph.D. (2002) in physical chemistry at the Institute of Problems of Chemical Physics at the Russian Academy of Sciences. Dr. Meteleva-Fischer is a two-year member of TMS.

Morita, Kazuki is a professor with the Institute of Industrial Science at the University of Tokyo where he earned his Ph.D. (1988) in engineering. Dr. Morita is a 14-year member of TMS.

Nowicki, Cassandre is a student in the Department of Mechanical Engineering at Laval Université and a one-year student member of TMS.

Qiu, Guibo is with the School of Materials Science and Engineering at Chongqing University in China and has been a member of TMS for one year.

Tafaghodi Khajavi, Leili is a Ph.D. candidate at the University of Toronto where she earned her M.S. (2009) in Materials Science. Ms. Tafaghodi Khajavi is a twoyear student member of TMS.
Tangstad, Merete is a professor in the Department of Materials Science and Engineering at the Norwegian University of Science and Technology, and has been a member of TMS for two years.

Tranell, Gabriella is a professor in the Department of Materials Science and Engineering at the Norwegian University of Science and Technology. She earned her Ph.D. (1999) in materials science and engineering at the University of New South Wales, Australia. Prof. Tranell is a two-year member of TMS.

Yang, Yongxiang is an assistant professor at Delft University. He earned his Ph.D. (1996) in Extractive Metallurgy and Materials Processing at Helsinki University of Technology. Dr. Yang is a 17-year member of TMS.

Zhang, Lifeng is the dean and a professor at the School of Metallurgical and Ecological Engineering at the University of Science and Technology Beijing, where he earned his Ph.D. (1998) in Metallurgical and Materials Engineering. He is the advisor to JOM from the Recycling and Environmental Technologies Committee and the chair of the Process Technology Modeling Committee. Dr. Zhang is an eight-year member of TMS.

\begin{tabular}{ll}
\multicolumn{2}{c}{ OTHER MEMBERS } \\
FEATURED IN THIS ISSUE \\
Diran Apelian & John Hryn \\
David Bahr & Warren Hunt \\
Cindy Belt & Robert Hyers \\
Bart Blanpain & Qizhen Li \\
Carl Cady & Brajendra Mishra \\
Srinivas Chada & Neville Moody \\
Robert Davis & Jadgish Narayan \\
Adrian Deneys & William Ready \\
Dennis Dimiduk & Wolfgang Schneider \\
Daneel Geysen & Art Schroeder \\
Brian Gleeson & James Sears \\
Kevin Hemker & David Alan Shifler \\
Hani Henein & George Spanos \\
Elizabeth Holm & Garry Warren \\
Other memmbers are listed in the sidebar "TMS Wel- \\
comes New Professional
\end{tabular}

